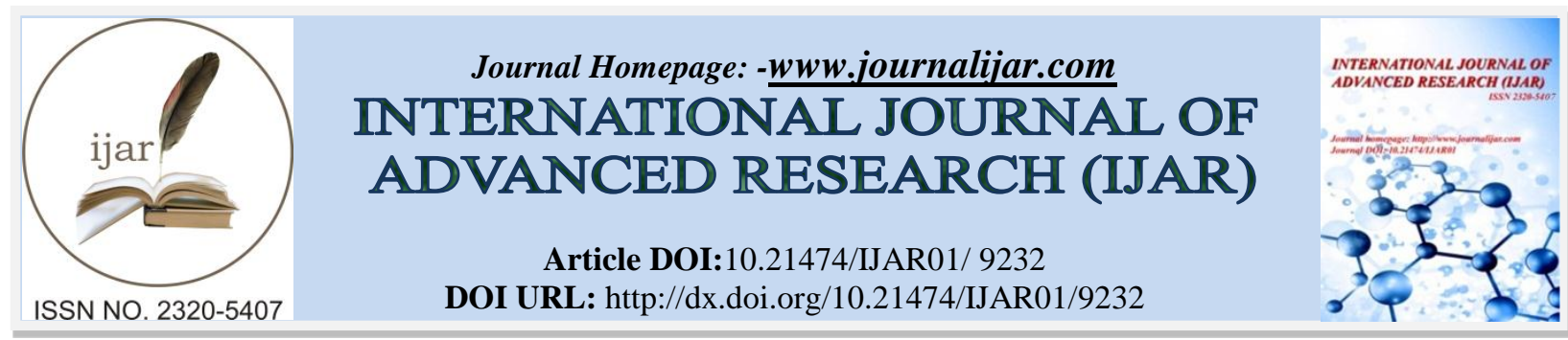

RESEARCH ARTICLE

\title{
PRACTICES AND CHALLENGES OF WATER SERVICE DELIVERY IN WOLAITA SODO TOWN, ETHIOPIA.
}

Naol Soboksa ${ }^{1}$, Feleke Solomon ${ }^{2}$ and Temesgen Tilahun ${ }^{2}$.

1. Ambo University, College of Business and Economics, Department of Public Administration and Development Management, Ambo, Ethiopia.

2. Wolaita Sodo University, College of Business and Economics, Department of Public Administration and Development Management, Wolaita Sodo, Ethiopia.

\section{Manuscript Info}

(.........................

Manuscript History

Received: 08 April 2019

Final Accepted: 10 May 2019

Published: June 2019

Key words:-

Challenges, practices, Wolaita Sodo town, water demand and supply.

\begin{abstract}
Access to water supply in Ethiopia is amongst the lowest in SubSaharan African countries. For instance in both urban and rural parts of the country, the existing service level is lesser than the required levels. Therefore, the study was intended to assess the practices and challenges of water service delivery in Wolaita Sodo town. To attain the objectives of the study descriptive research design was implemented. Both primary and secondary sources were used to obtain all necessary data for the study. Specifically the study conducted on 199 households that selected from Wolaita Sodo town residents using stratified sampling technique. Questionnaires, interview and document analysis were used to collect data concerning the practices, accessibility and challenges of water supply in the town. The result of the study illustrates that water supply is very poor and below the standard that set by World Health Organization in Wolaita Sodo town. It is quite evident that rapid population growth, frequent interruption of water supply, poor management, lack of budget, and low participation of community and other stakeholders were mainly restrains water services delivery in the town. Because of this the gap between demand for water service and its supply is increasing. Therefore, Water supply and sanitation department, NGOs, communities, and private sectors should be actively engaged in crafting and applying various projects to provide safe water service delivery in the town.
\end{abstract}

Copy Right, IJAR, 2019,. All rights reserved.

\section{Introduction:-}

The availability and accessibility of clean water is mostly significant for the survival of human being. Thus, provision of quality and safe water services has become a major concern in both developed and developing countries (Armstrong and kilter, 2008). However, in most developing countries there is deficiencies in the coverage, accessibility and quality of water supply and sanitation services are common(OECD, 2010). For-example in the world more than one billion people lack access to safe drinking water. As a result around 1000 children was died every day from diarrhea caused by contaminated water, poor sanitation and improper hygiene, that is more than AIDS and malaria combined (WHO, 2012).

Corresponding Author:-Naol Soboksa.

Address:-Ambo University, College of Business and Economics, Department of Public 
In Africa urban population close to one billion. However among them only limited number of community have access to clean water and sanitation service in the continent. In Ethiopia the development of modern water service goes back to the time of Emperor Mennellick II, when the first water supply constructed in 1898 E.C from Entoto Mountain to great palace of Mennellick II in Addis Ababa and then pursued to Dire Dawa in 1900 E.C, by French construction of railway purpose. During that time most of the population has no access to safe and adequate supply facilities. This unsafe and inadequate water supply, particularly unbalanced to population led to communicable diseases (Asnake 2012).The estimated water service level of Ethiopia in terms of coverage, quantity, quality, and reliability is among the lowest in the world. These combine effect of the poor water supply and sanitation facilities in the country have high impact on the economic development of the country and the living condition of the towns' communities (UNDP, 2006).

In this context Southern Nations Nationalities and Peoples Regional state has no exception. This region has huge water potential in the country which obtains from rivers, lakes streams and ground water. However, the adequacy and accessibility of urban water supply is at infant stage. In most urban areas like Wolaita sodo town, water scarcity becomes a significant and growing problem. Provision of water service is not balanced with the fastest rate of population growth. This is mainly due to poor budget utilization, regional topography, reduction of water from its sources because of climatic change, the settlement form and so forth (SNNPRWNRA, 2011).

In Wolaita Sodo town, there is a large volume of water potential. Nevertheless, the residents of the town cry always about shortage of water. The fundamental problems for such water crisis are broadly related to the problem of governance like lack of transparency, responsiveness, effectiveness, accountability, and voicing mechanisms over services. Beside this, rapid population growth and the expansion of hotels, restaurants, ad construction of large organization like Wolaita Sodo University have contributed for water crisis and shortage in the town (Wolaita Development Association, 2013). These and other related problems necessitated the need to conduct the study on the practices and challenges of water service delivery in Wolaita Sodo town.

\subsection{Statement of the problem}

Water covers around $75 \%$ of our planet and it is easy to think that it will always be plentiful. But around 1.1 billion people worldwide lack access to water and a total of 2.7 billion find water scarce for at least one month of the year. Water and sanitation problems rises due to climate change and good governance constraints like lack of accountability, responsiveness, transparency, efficiency and effectiveness and other related factors(WHO, 2012).

In Africa, nearly $87.5 \%$ of people do not have access to clean and safe water that is the equivalent of one in eight people on the planet. So with unclean water sources after miles from villages, many of the able bodied members of community are forced to spend hours each day simply on finding and transporting water. The United Nations estimates that sub Saharan Africa alone lose 40 billion hours per year collecting water. The economic and social effects caused by lack of clean water are often the highest priorities of African communities when they speak of their own development. In economic terms for every $\$ 1$ invested in the water and sanitation, there is an economic return between $\$ 3$ and \$334.In Ethiopia only $24 \%$ of the population has access to drinking water and only $13 \%$ of them have basic sanitation service. Access to potable water service is amongst the lowest in Sub-Saharan Africa and the entire world. Hundreds of people fail on ill and die daily due to drinking contaminated water. That is why women and girls travel huge distances to fetch water (Chala, 2011).

Southern Nation, Nationalities and Peoples Regional State relatively characterized by infrastructural developed regions in the country. However, in the region there is a continuous problem of water supply and sanitation service delivery. This is mainly because of high regional population growth, lack of finance and skilled personnel, poor community's habit in utilization of the services, ambiguous responsibilities between zone, Woreda and water committees. As a result, the region shares only $11.5 \%$ of water supply and sanitation service of country's $39.4 \%$ and $63.9 \%$ of water comes from unprotected sources of water as compared to only $35 \%$ of water supply sources comes from protected springs, public and privet tap (SNNPRPDB, 2013).

In this case Wolaita Sodo town has the largest volume of water potential. In the area there are two sources of water these are ground and streams water sources including 'Goje', 'Akimse', and 'Damota' streams. Nevertheless, the residents of the town still cries about shortage, absence and lack of pure and safe of water. The major reasons are mainly related with lack of good governance (i.e. transparency, accountability, efficiency, effectiveness, and voicing mechanism over poor services). In addition, population growth, topography of the town, ill budget utilization and 
seasonal fluctuation in volume of water from its sources also affect the provision of water supply in the town. Earlier studies conducted on water supply and sanitation service delivery both at national and regional levels focused mainly on big cities. But in small and medium towns like Wolaita sodo towns, not adequate research yet carried out. Moreover, the provision of water and sanitation services is clearly observed as critical challenges in the town. This situation necessitated research work to look at the issues in the area closely and deeply in order to give clear description of the problems from various urban residents and administrators point of view.

\subsection{Objectives of the study}

The fundamental objective of the study is to assess the practices and challenges of water service delivery in Wolaita Sodo town. Specifically the study aims to:

1. Examine water service delivery in terms accessibility, cost and time in Wolaita Sodo town

2. Find out the major sources of water and their relative contribution to water supply

3. Identify the challenges affecting water service delivery in the town

\section{Review of Related Literature}

\subsection{Urban Water Supply in Ethiopia}

In Ethiopia water supply sector is one of the least developed sectors and it is mostly characterized by service deficiency due to poor physical infrastructure, inadequate management capacity to handle policy and regulatory issue and to plan, operate and maintain water service delivery. Ethiopia has the highest urbanization growth rates in developing countries. According to the data obtained from central statistics authority, the country's urban population was growing at $4.8 \%$ per annum between 1995 and 2003.The urban population in Ethiopia in 2007 was $16.1 \%$ of the total population. Available data also indicate that in the next 25years (1994-2020), nearly 30 percent of Ethiopia population will live in towns/or cities. This kind of rapid urban population growth will inevitably call for huge investment in housing, urban infrastructure, water supply, electric power, sanitation system and environmental protection programs to alleviate poverty and unemployment in the cities.

This implies that the challenge will need well trained municipal management and adequate resources, responsive urban governance and well trained and motivated personnel and sustaining service such as water, electricity supply, local revenue collection and administration to meet the ever growing demand for better and more quality service and infrastructures. With regard to the distribution of water, the welfare monitoring survey of 1996 estimated that 36 percent of the households use own tape while 61 percent use public tap or Bono water (FDRE Central Statistical Agency, 2007).

There is also regional variation both in urban areas such as Addis Ababa, Dire Dhawa and Harar in particular showing more percentage of population with access to safe source of water. Afar, Benishangul Gumuz, and Gambella regions have low percentage population with access to safe water. Another key issue in urban area is low pace of progress in water service delivery because of lack of comprehensive legislation, inadequate investments and resources, lack of effective national water tariff policy, absence of beneficiary participation and communication management (Desalegn, 2009).

\subsection{Challenge of sustainable urban water supply}

In the provision of adequate clean water to urban dwellers, the work faced many challenges, which are related to capacity of the nation, i.e. technological knowhow and institutional), in adequate finance, rapid urbanization and declining of global water resources.

\subsubsection{Lack of capacity}

According to Wallace and etel. (2008), capacity is a flexible concept and encompasses the public sector, academia; community based organization and the private sector and ranges from the individual to institutions to institutions society as a whole capacity can be described in terms of the human technological infrastructural institutional and manage mental resources required at all levels from the individuals through to national government. Not only does capacity have to be built within each of these levels but it must be institutionalized and local communities need to be empowered to use it effectively. Additionally, capacity building includes the following.

1. Capacity to engage, educate and train; including community awareness building, adult training and formal education. So as to provide sufficient numbers of competent human resources to develop and apply enabling system within the local environment. 
2. The capacity to measures and understand aquatic system through monitoring applied research technology development and forecasting.

3. The capacity to develop policies and program to legislate regulate and achieve compliance through effective governmental and private sector institutions and through efficient enforcement and community acceptance, particularly for rural areas.

4. The capacity to identify and provide appropriate and affordable water technologies, infrastructure service and products through sustained research, investment and management.

\section{Inadequate financing}

Historically water suffered from severe under financing. This result from inadequate internal financial capacity that exist in the poor countries to achieve water goals; poor political decisions for allocation of development aid; an overall reduction over time in development aid; and the limited cost recovery potential of the sectors in poverty stricken regions. For example, for 2005 water supply millennium development goals needs assessment report by the government of Ethiopia estimates the investment requirement for water at us \$ 297 million per year for the next years (2006-2015), per capital investment for water in urban and rural areas is US \$ 105 and US \$ 41 million respectively. Total government allocation and committeemen for WSS over the next seven years has been projected at 12 million (US \$ 5.4) million for rural, and US \$ 6.6 million for urban. Despite high investment by various donors, the country faces shortage of 197 million per year (WHO, 2012).

Furthermore, prioritization of spending plays an important role with many developing countries investing only a small portion of money in to water compared with military spending. For instance, military spending in Ethiopia 10 times greater than money that spent on water supply and sanitation sector. These and other factors hinder the country in ensuring sustainable water and sanitation service delivery (UNDP, 2006, Chala, 2011). I

\subsubsection{Population growth and urbanization}

Population growth and urbanization will create a severe scarcity of water and it posesa tremendous impact on the natural environment. According to UNDO, 2006) in least developed countries urban population will grow at rapid pace. Besides having less or not invested in urban infrastructure, in Africa urbanization faster than any other regions. Between 1990 and 2015, the total urban population of the region is expected to grow from 300 to 700 million; and by 2020 , it is expected that over $50 \%$ of the population in Africa countries will reside in urban areas. These hampers water supply and sanitation service delivery.

According to the 1994 Ethiopia population census report showed, the total urban population 7,323,122(13.7\% of total population), after ten year (i.e. 2004) the total urban population increased to $17,588,735(33 \%)$ and by the years 2015 urban population is going to increase by $22,925,177(32,26 \%)$. This creates imbalance between water supply and demand for water in most of the towns /or cities (Chala, 2011).

\subsection{Conceptual frame work}

Figure 1:-Conceptual framework

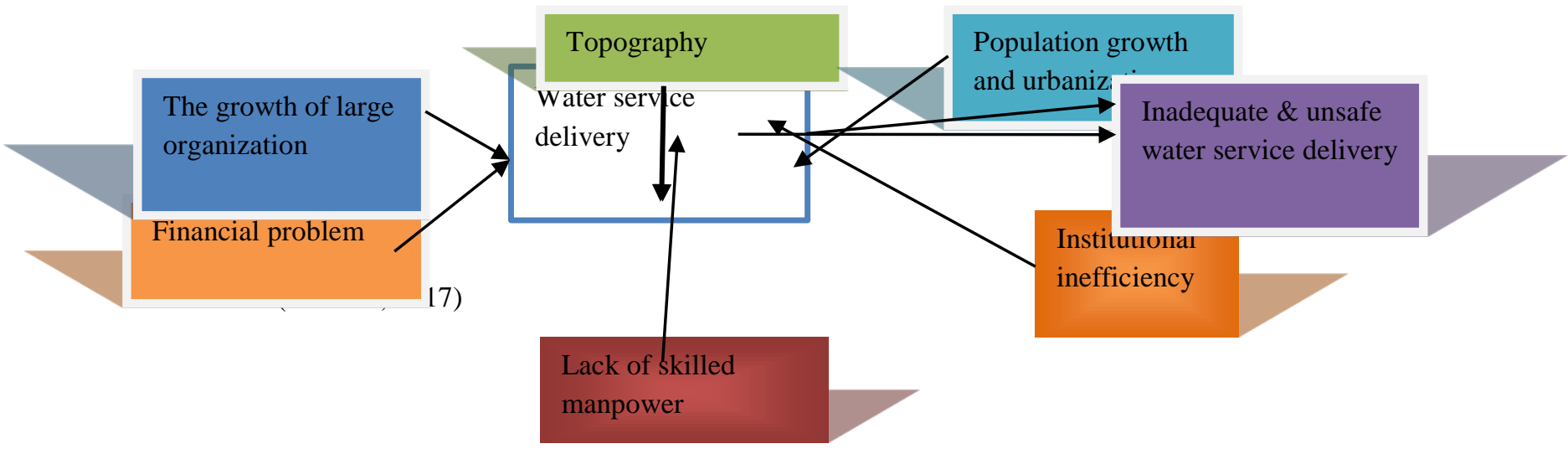

\footnotetext{
Research Methodology

Description of Research Area
} 
Wolaita sodo town is located in southern part of Ethiopia, in Southern Nation Nationalities and People's Regional State, in Wolaita zone. It is found at a distance of $329 \mathrm{~km}$ from Addis Ababa and $167 \mathrm{~km}$ from regional city Hawassa. There are around three sub-cities, which include 'Arada kifleketma', 'Merkato kifleketma' and 'Mehale ketema'. The geographic coverage of the town is $509.90 \mathrm{~km}^{2}$ and around 86,050 peoples are there with population growth rate of $2.5 \%$ per year. Among these peoples 7349 of them are registered households for water service.

The town water service department was established in 1994E.c with proclamation number of 40/1994.The department consists of 78 employees. The town has agro ecological zone of "Woynadega" and topographically lies on altitude of $1483 \mathrm{~m}$ above sea level and has a sloppy topography. And also it is amongst the growing towns in the region with good infrastructural facilities. Of course, there are many services in the town which are being provided in a good manner. However, in contrast to this, the development of water service delivery is at infant stage. As a result accessibility and adequacy of the service is not satisfactory. There are some major bottle necks to service including series increase in number of population and administrative related problems like inefficiency, ineffectiveness and non-transparency (Wolaita Development Association, 2012).

\subsection{Research Design}

The descriptive research design was used to carry out the study. This research design comprises both quantitative and qualitative method. Quantitative method was used in undertaking numerical analysis and interpretation of result whereas qualitative approach was used to describe and narrate the problem under investigation. Descriptive research is used when researchers want to explain events as they happen and report the facts on the ground and make judgment as to what ought to be done. Since it provides opportunity to gather all necessary and detail information that enables the researchers to easily understand and interpret the result. Also it specifies the approach that used for gathering the data; it indicates the target population and methods used in processing and analyzing of the collected data.

\subsection{Sources of Data}

Both primary and secondary data was used. Primary data has been collected from residents and workers of Wolaita Sodo water supply and sanitation sector. The primary data has been collected through questionnaires and interview. On the other hand, secondary data has been gathered from book, articles, journals, reports and other published and unpublished documents relevant to the topic. The primary sources of data enables us to obtain information relates to what is currently happening; determine techniques that were used to obtain accurate data for the study. Secondary sources of data have been used to substantiate the information that gathered from primary sources. Moreover, secondary data gathering is less time consuming and cheap than primary sources of data. However, either of them may not provide sufficient information so that both were used simultaneously.

\subsection{Sample Size and Sampling Techniques}

Sample size determination is not about reducing sample error or increasing representativeness, rather it is concerned with the objective of gathering sufficient data that can effectively address the research question and enhance validity and reliability of the study. For this study to gather sufficient data the researchers selected 199 customers from 7349 households that registered for water service in Wolaita Sodo town. Wolaita Sodo town has 10 Kebeles or units and these kebeles/or units were used as strata. Accordingly, each strata has a registered household for water service, their number was 457, 328, 434, 293, 355, 2476, 203, 1845, 662, and 296 respectively.

Thus sample size was proportionally taken from each Kebele using $\mathbf{n}=\mathbf{n} * \mathbf{N i} / \mathrm{N}$ formula where, $\mathbf{n}=\mathbf{r e q u i r e d}$ sample, $\mathrm{Ni}=$ population in each stratum $\mathrm{N}=$ total population (sum of registered households and employees (7349). Thus, a stratified sampling method was used to take sample for the study. Structured interview were conducted with the officials and experts in water supply and sanitation sector to acquire additional information for the study.

Table 1:-sample taken for the study

\begin{tabular}{|l|l|l|} 
Kebele/Stratum & Total HHs registered in each Kebele & Sample size selected from each Kebele/strata
\end{tabular}




\begin{tabular}{|l|l|l|}
\hline 01 & 457 & 12 \\
\hline 02 & 328 & 9 \\
\hline 03 & 434 & 12 \\
\hline 04 & 293 & 8 \\
\hline 05 & 355 & 10 \\
\hline 06 & 2476 & 67 \\
\hline 07 & 203 & 6 \\
\hline 08 & 1845 & $\mathbf{5 0}$ \\
\hline 09 & 662 & 18 \\
\hline 10 & 296 & $\mathbf{8}$ \\
\hline Total & & 199 \\
\hline
\end{tabular}

\subsection{Methods of Data Collection}

This research utilizes a variety of data gathering tools to collect data from different sources. Qualitative and quantitative methods of data collection were used so as to triangulate and check the validity of information that collected from different sources. Specifically questionnaire, structured interview and desk review have been used to collect data. Primary data has been collected using questionnaire and structured interview whereas secondary has been collected using extensive desk review or document analysis.

\subsection{Methods of Data Analyzing}

The researchers intended to assess the practices and challenges of water service delivery in Wolaita Sodo town. Therefore, to analyze the data which collected through questionnaire and interview, descriptive method of data analysis was used. Quantitative method of data analysis was used to analyze quantitative data whereas; qualitative method of data analysis like narration and explanation was used to analyze qualitative data that collected via interview and open ended questionnaire.

\section{Results and Discussion:-}

\subsection{Water Supply in Wolaita Sodo town}

\subsubsection{Water Production in Wolaita Sodo town}

The main source of water supply and distribution in Wolaita Sodo town are both surface and ground water sources. These include 'Goje', 'Likimse' and 'Damota'. That means 'Goje' and 'Likimse' are streams, but 'Damota' is ground water source. Annual water production, distribution and non-revenue water of Wolaita Sodo town from 2011-2015 EC were discussed as hereunder.

Table 2:-Annual Water Production, Distribution and Non- Revenue Water (NRW) in Wolaita Sodo

\begin{tabular}{|l|l|l|l|l|}
\hline Year & Production $\left(\mathbf{m}^{\mathbf{3}}\right)$ & Distribution $\left(\mathbf{m}^{\mathbf{3}}\right)$ & Loss $\left.\mathbf{( m}^{\mathbf{3}}\right)$ & NRW $(\boldsymbol{\%})$ \\
\hline 2011 & 1634804 & 1317190 & 317614 & 19.43 \\
\hline 2012 & 1297960 & 1120165 & 177795 & 13.7 \\
\hline 2013 & 2181156 & 1143789 & 934945 & 42.86 \\
\hline 2014 & 2301245 & 1246211 & 1050034 & 45.6 \\
\hline 2015 & 2322057 & 1031028 & 1291029 & 55.6 \\
\hline
\end{tabular}

Source (Wolaita Sodo Water Supply and Sanitation Sector, 2015)

From the table 4, it is shown clearly that every year because of leakage problem significant proportion of the produced clean water loss before it reaches the consumers or final users. In the distribution system there are old pipelines that have been laid by Wolaita Sodo Water Supply and Sanitation Sector. This reveals that because of leakage large volume of clean water is duplicated before it being utilized.

\subsubsection{Water Distribution in Wolaita Sodo town}

The system of distribution is the most important aspects of water supply in Sodo town and everywhere as whole. These system and efficiency of water affects the supply and its consumption. The process of distribution starts from the place of production of the water. In this case it begins from boreholes, streams and surface water as well. According to Wolaita Sodo water supply and sanitation sector, the total estimated length of distribution is greater than $50 \mathrm{~km}$ with the varying pipe size. 
Table 3:-When often do you get water service?

\begin{tabular}{|l|l|l|}
\hline Category (rate) & Frequency & Percentage (\%) \\
\hline Daily & 22 & 11 \\
\hline Twice a week & 58 & 29 \\
\hline Every three day/ week & 93 & 47 \\
\hline Once / a week & 16 & 8 \\
\hline Once per two weeks & 10 & 5 \\
\hline Total & 199 & 100 \\
\hline
\end{tabular}

(Source: own survey, 2016)

The above table shows that around $89 \%$ of households have no access to water service on the daily basis whereas the rest $11 \%$ of households have access to water on the daily basis. This means water is accessible to households (HHs) every three days/week, twice/week, once/week and once per two weeks mostly due to power break down and the summer overflow of water into the treatment plant.

\section{Equitable distribution of water service among sub- cities}

As shown in the below table figure relatively the largest 141(71\%) of respondents confirmed that there is no adequate and equal distribution of water service among sub cities while $58(29 \%)$ of respondents responded in otherwise. This implies that there is no fair and equal distribution of water service among or between Wolaita Sodo sub- cities. Many factors can contribute for this unfair distribution of water service delivery. Among these topography is one of a major factor that affects evenly distribution of water service in town. For instance, 'Aroge Arada' sub city's land feature is relatively convenient as compared to other sub cities. On the other hand, the potential source and number of hotels and large organizations in each sub-city is also another factors. This is consistent with an interview results that conducted with the management of water supply and sanitation sector. It discloses that the production and distribution of water service are inefficient and not match with the demand of the society. This imbalance between water supply and demand challenges the lives of community who reside in the town at large.

Figure1:-Equitable distribution of water service among sub- cities

\section{Equitable Distribution of water service amongest subcities}

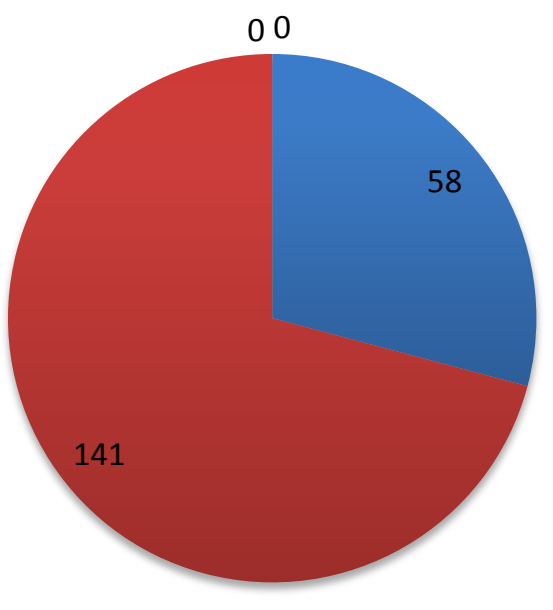


Currently water supply has been moderately increasing in Wolaita Sodo town. However, it doesn't satisfy the current need and demand of water that exist in the town. This means that the number of urban potable water supply coverage has not been increased as the number of urban population who demand potable water is slightly increasing from time to time. This shows that the rate of population growth is greater than the rate of water supply in the town. This imbalance between water supply and demand is common and still increasing due to the shortage of water supply. In line with this the respondents were asked to evaluate the current status of water supply as high, medium or low in Wolaita Sodo town.

Table 4:-what is the current status of water service delivery in Wolaita Sodo town?

\begin{tabular}{|l|l|l|}
\hline Item & Respondents \\
\hline & Frequency & Percentage \\
\hline High & 23 & 11.6 \\
\hline Medium & 65 & 32.6 \\
\hline Low/ poor & 111 & 55.8 \\
\hline Total & 199 & 100 \\
\hline
\end{tabular}

(Source: own survey, 2016)

Form the table it was observed that the majority (56\%) of the respondents have seen water supply as it is low and below the standard that set by Millennium Development Goals (MDGs) followed by medium and high which accounts $32 \%$ and $16 \%$ respectively. Thus water service delivery is inadequate, inaccessible and doesn't satisfy the current demand for potable water service that exists in Wolaita Sodo town.

\subsubsection{Water Accessibility in Wolaita Sodo town}

Water accessibility is an amount of water, which is needed to satisfy metabolic, hygienic and domestic requirement at least 20 liters of safe water per person per day and not more than 200m away from residence (WHO, 2008). In line with the respondents were asked to answer whether water service delivery is accessible to them or not and their response were analyzed as here under.

Figure 2:-Accessibility of water service in Wolaita Sodo town

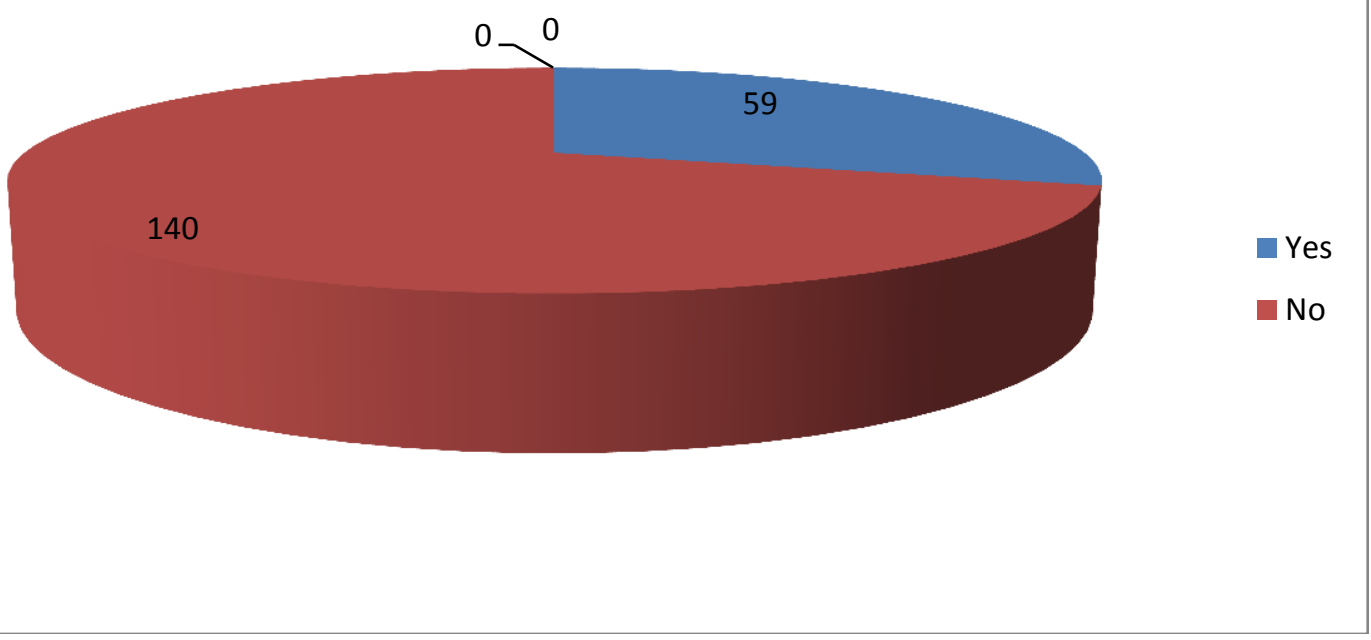

The respondents result indicated that out of 199 sampled respondents the majority 140(70\%) of respondents responded that water service is inaccessible whereas 59(30\%) of them said that there is an accessibility of water service delivery in the town. This study reveals that the number urban potable water supply coverage has not been increased as the number of urban population is slightly increasing from time to time. As a result of this the demand for water supply is high in the town and it enforces people to collect unsafe and unprotected water from river and hand dung sources.

\subsubsection{The Major Source of Water Supply in Wolaita Sodo town}


People of the town get water from both piped system and /or non-piped system. Piped water supply is the fastest and reliable sources of water while non-piped system are unprotected and un safe, which includes revivers, lakes hang dug wells and other un protected sources. Hence, as sodo town is an old and fast growing town, Wolaita Sodo water supply and sanitation organization is only producer and supplier of pipe water service to urban dwellers. Therefore, households in the study area get piped water through different connection system as shown in the following table.

Table 5:-What are the major sources of water in Wolaita sodo town?

\begin{tabular}{|l|l|l|}
\hline Item & Response \\
\hline & Frequency & Percentage \\
\hline Private tap & 66 & 32.2 \\
\hline public tap & 51 & 29.2 \\
\hline vendor & 40 & 20.1 \\
\hline Total & 199 & 100 \\
\hline
\end{tabular}

(Source; own survey, 2016)

The study shows that the majority $66(32.2 \%)$ of the respondents were reacted that they can get water services from private tap whereas the rest 35(17.5\%), $58(29.2 \%)$ and $40(20 \%)$ of respondents were collected water from yard tap, public tap and water vendor sources respectively. This implies most households get water from private tap. Furthermore, according to information collected from a manager of water supply and sanitation sector, most of the people rely on public tap and water vender that exist in the town because of lack of finance, shortage of water supply, more complicated procedures of the sector in getting private connection and unavailability of public tap at nearly and installation material and connection tasks involve much higher costs which depend on the location of house from their water networks.

\subsubsection{Distance from home to water source}

As mentioned above, most of the people who reside in Wolaita Sodo town get water from two main sources such as piped system and/or non-piped system. Piped water supply is the safest and reliable sources of water while nonpiped systems are unprotected and unsafe, which includes rivers, lakes, hand dug wells and other unprotected stream sources. Since the town is an old and fast growing town in Southern Nations, Nationalities and Peoples regional state, residents are supplied with piped water which is only produced and supplied by water supply and sanitation sector.

However, the water supplied in the town cannot meet the demands of the living people. Accordingly, the households confirmed that they enforced to travel long distance which takes more than 30 minutes return trip to fetch water for their daily life. Such type of problem is very common in Wolaita Sodo town sub cities and kebeles. The residents pointed out that most public taps that found in the town are closed for unknown and unrecognized reasons. Besides this, the seller closed tap and leave the place before their turn reaches. Thus, most of people prefer to buy from private water vendors that exist in the town. And those people who cannot travel long distance may pay up to 1 Ethiopian birr per a container which holds 20 litters. An interruption of water supply highly bothered women and children who reside in Wolaita Sodo town. They suggested that, it is very difficult to get a continuous water supply in the area and in addition to this women and children are bothered about interruption of water supply in the town.

Table 6:-How much meter you travel to fetch water?

\begin{tabular}{|l|l|l|}
\hline Distance travelled to collect water $(\mathrm{m})$ & Respondents & Percentage \\
\hline & Frequency & 11.9 \\
\hline Less than $100 \mathrm{~m}$ & 24 & 15 \\
\hline $200-500 \mathrm{~m}$ & 29 & 62.3 \\
\hline Above $500 \mathrm{~m}$ & 124 & 10.8 \\
\hline Total & 22 & 100 \\
\hline
\end{tabular}

(Source: own survey, march 2016)

According to the table above 8 out of 199 total respondents $24(11.9 \%)$ them get water from primary sources at less than 100 meters whereas, 29(15\%) of the households get their water at 200 meter. Also 124(62.3\%) household get in between $200-500 \mathrm{~m}$ distance which is together with in a basic access range, but 22(10.8\%) households travel over 
$500 \mathrm{~m}$ to fetch water from the source. This implies that most of households who reside in the town are collecting water after travelling a long distances. As some research shows, in urban area about 52 percent of the population traveled a long distances to reach the nearest water source and this directly affects women and children who are mainly responsible for fetching water.

\subsubsection{Water Collection Time}

The collection of water varied considerably with the primary source of water that household use. Household with stand pipe or public tap and vendor source type cover the longest time per trip, whereas households with privet house and yard connection sources travel short distance. According to the discussion made with households some of them spend over an hour to collect water. For further information see the table 13 hereunder.

Table 7:-How many minutes you will spend to fetch water?

\begin{tabular}{|l|l|l|}
\hline Time to collect water(minutes) & Respondents \\
\hline Less than 5 minutes & Frequency & Percentage \\
\hline $5-30$ minutes & 19 & 9.5 \\
\hline Above 30 minutes & 123 & 61.9 \\
\hline Total & 57 & 28.6 \\
\hline
\end{tabular}

(Source; own survey, 2016)

According to the above table9, especially if we consider public tap users, out of 199 total respondents, 19 (9.5\%) of respondents travel less than 5 minutes in order to fetch water for their daily lives. Whereas, the rest $123(61.9 \%)$ and $57(28.6 \%)$ of households travelled 5-30 minutes and more than 30 minutes for single trip in collecting water respectively. Therefore, most of public pipe users travel a long distance and spent much time on fetching water from its sources Thus, most of households have easily exposed to health, social, economic crisis and the like.

\subsection{Water Tariffs}

Water tariff is also the major determinant of water accessibility. Basically there are two types of water tariff, which are connection tariff and usage tariff. Connection tariff includes installation, material and connection tasks while usage tariff depends up on the amount of water used with additional meter. The usage tariff a mixed system i.e. uniform tariff rate for public tap and blocked tariff with progressive rate tied to consumption for service connection. The service charge imposed on water has significant influence on the selection and consumption of water. Household with low level of access to safe water supply frequently pay more tariff than household connected or registered for public water service system.

However, the fairness of the price set for the private connection to the poorer section of community on one hand and on the basis cost recovery on the other hand answerable. The operational tariff for Wolaita Sodo water service organization is progressive tariff with the lowest band consumption tariff of ETB $4 / \mathrm{m}^{3}$ and the highest in the brand at ETB $5.75 / \mathrm{m}^{3}$.Public tap users paying using flat Wolaita charge tariff system and it is ETB $5 / \mathrm{m}^{3}$ (WSWSS, 2016).

Table 8:-The current and proposed water service tariff in Wolaita Sodo town

\begin{tabular}{|l|l|l} 
Consumption Brand $\left(\mathrm{m}^{3}\right)$ & Current Tariff $\left(\mathrm{ETB} / \mathrm{m}^{3}\right)$ & Proposed Tariff $\left(\mathrm{ETB} / \mathrm{m}^{3}\right)$
\end{tabular}




\begin{tabular}{|l|l|l|}
\hline $0.1-3.0$ & 4.0 & 5.0 \\
\hline $3.1-6.0$ & 4.25 & 5.25 \\
\hline $6.1-10$ & 4.5 & 5.5 \\
\hline $10.1-15.0$ & 4.75 & 5.75 \\
\hline $15.1-25.0$ & 5.0 & 7.00 \\
\hline $25.1-40.0$ & 5.25 & 8.25 \\
\hline $40.1-100.0$ & 5.5 & 10.5 \\
\hline Above & 5.75 & 12.75 \\
\hline
\end{tabular}

(Source: WSWSO, 2016)

As we can observe from the table 10, for private pipe connection users, tariffs or service charge paid is increased based on their level of consumption. This means after a certain limit of consumption, the tariff remains the same that is $5.75 / \mathrm{m}^{3}$ This pricing approach subsidizes the high income level households and increase a burden on a poor community section, especially on those public tap users because they are paying a flat charging system.

Table 9:-Do you think that the current tariff is reasonable?

\begin{tabular}{|l|l|l|}
\hline Category & Respondents \\
\hline & Frequency & Percentage \\
\hline Yes & 121 & 60.8 \\
\hline No & 78 & 39.2 \\
\hline Total & 199 & 100 \\
\hline
\end{tabular}

(Source: own survey, 2016)

The above table deals with the reasonability of current tariffs. Accordingly out of 199 total respondents the largest share $121(60.8 \%)$ of the respondents were said that the current tariff is high whereas the rest $78(39.8 \%)$ of them were rated the tariff that set and imposed on water consumption is low in the town. Therefore, it is not easy to lower the price of water below the currents amount and even, it has been raised as shown in the table above.

Table 10:-Are you willing to pay for water service?

\begin{tabular}{|l|l|l|}
\hline Category (ETB) & \multicolumn{2}{|c|}{ Respondents } \\
\hline & \multicolumn{1}{|c|}{ Frequency } & Percentage \\
\hline Less than 0.5 & 16 & 8.2 \\
\hline $0.5-0.75$ & 111 & 55.8 \\
\hline $0.75-1.00$ & 46 & 23 \\
\hline Above 1.00 & 26 & 13 \\
\hline Total & 199 & 100 \\
\hline
\end{tabular}

(Source: own survey, 2016)

The above reveals that out of 199 total respondents,16(8.2\%) and 111(55.8\%) of respondents reported that they were willing to pay less than ETB 0.5 and $0.5-0.75$ ETB per a container which holds 20 litters respectively while the remaining $46(23 \%)$ and $26(13 \%)$ of respondents pay $0.75-1.00$ ETB and above 1.00ETB respectively. This indicates that majority of households are willing to pay. Even though, they are willing to pay service that imposed by Wolaita sodo town water service organization, they sometimes are enforced to pay high and flexible service charge from 2ETB -3ETB, which is somewhat immoral.

\subsection{Water interruption in Wolaita Sodo town}

The study reveals that households fetch water from various sources private tap, public tap, water vender and yard tap. This does not mean that the service is adequate and continuous, rather water interrupts is very common in Wolaita sodo town. The main reasons that contribute for water interruption in the town were discussed in the table 11 hereunder.

Table 11:-What the major reasons for water service interruption in the town?

\begin{tabular}{|l|l}
\hline Item & Respondents \\
\hline
\end{tabular}




\begin{tabular}{|l|l|l|}
\hline & Frequency & Percentage \\
\hline Population growth and topography & 65 & 27.63 \\
\hline Management problem & 76 & 38.2 \\
\hline Electric power supply shortage & 40 & 20.1 \\
\hline Reconstruction and maintenance & 12 & 6.03 \\
\hline Limited capacity of reservoirs and others & 16 & 8.04 \\
\hline Total & 199 & 100 \\
\hline
\end{tabular}

(Source: own survey, 2016)

Based on the above table 13, from the total respondents, 65(27.63\%) of them answered that the reason for water interruption was rapid growth and topography. The rest $76(38.2 \%), 40(20.1), 12(6.03 \%)$ and $16(8.04 \%)$ of respondents answered that the cause for interruption of water service is population growth and topography, management problem, electric power supply, shortage, reconstruction and maintenance and limited capacity of reservoirs respectively. This means that the management or administration problem, population growth and shortage of electric supply lead to water interruptions in Wolaita sodo town. Similar study have been carried out by Asefa Delesho(2006). He also reported the difficulties in unavailability of water supply in Asosa town of Ethiopia. The town was unable to the demand for water mainly because of institutional, financial, human and mater resources constraints. Chala Deyessa (2011) and Mokenonen and R.Uttama(2014) have reported the shortage of water supply, high cost of piped water connection, length process during connection and frequent interruption.

\subsection{The Alternative Water Source during interruption}

During the interruption of primary source, most of the households reported that they use different types of source as a secondary source. The percentage distribution of those secondary sources in Wolaita sodo town is shown in the table below.

Table 12:-what is the alternative source of water during interruption?

\begin{tabular}{|l|l|l|}
\hline Item & Respondents & \\
\hline & Frequency & Percentage (\%) \\
\hline Vendors & 96 & 48.2 \\
\hline Public tap & 45 & 22.6 \\
\hline Yards tap & 23 & 11.6 \\
\hline Private tap & 29 & 14.6 \\
\hline Rain water sources & 6 & 3 \\
\hline Total & 199 & 100 \\
\hline
\end{tabular}

(Source: own survey, 2016)

As shown in the above table 14, out of 199 sample respondents the majority of them uses water vendors as secondary source of water during interruption which account $96(48.2 \%)$ followed by public tap $45(22.6 \%)$ and the rest $23(11.6 \%) 29(14.6 \%)$ and $6(3 \%)$ of them uses yard tap, private tap and rain water source respectively. This clearly reveals that inaccessibility of public tap in particular and inefficiency of water service in the town as whole. Due to this reason mostly the poorer section of community could never afford up with water vendors charge.

\subsection{Challenges Affecting Water Service delivery in Wolaita Sodo town}

As a literature shows, addressing the problem of water service delivery would be very easy if the root causes of poor service delivery were easily recognizable and understood in water supply i.e. production and distribution of water. As a result, the respondents were asked to identify the main challenges that contribute for inadequate, inaccessible and unaffordable water service delivery in the town. Among them limited capacity of Nation, regional and zone (technological and institutional incapability; inadequate finance, decline of water sources, shortage of water and destruction of water boreholes, rapid urbanization and shortage of pumping machines are very common in Wolaita sodo town water supply. In line with this, the interview that conducted with some of the employees of water supply and sanitation sector revealed the constraints that hinder the sector in delivery of water services. These includes:-

\section{Rapid growth of population:}


The continuous growth of population in the town due to the natural increase \& migration coupled with the expansion of the town imposed higher burden up on the utility of organization of the town and it becomes difficult to accommodate the ever growing population. In general, the problem exacerbated by the failure to design optimum use of water for the town due to underestimation of population growth based on the national population growth while growth rate for Sodo town is high (i.e. $2.5 \%$ ).

\section{Frequent supply interruption:}

The frequent interruption of the supply that reduced the actual production less than the expected amount. In addition to this, the limited numbers of boreholes with decreasing water volume because of siltation has aggravated the situation, road construction and maintenance.

\section{Loss by leakage:}

Is the major cause of widening of gap between water demands supplies in the sodo area. In addition to the under capacity rate of production which lower down the actual production of water supply, water loss has further reduced the amount of water supply.

\section{Management problems:}

Management problems in this town caused by inefficient organizational structure, under staffing, low employees' salary, lack of staff motivation, and inability of the water supply and sanitation sector to retain trained \& experienced staffs are the main constraint to service delivery.

\section{Limited budget and funds:}

Since the delivery of urban water supply require high level of investment. But, lack of sufficient funding has limited the quantity of water supply service of Wolaita Sodo water service organization. Even though, the current cost recovery mechanism of the sector seems better and able to cover expenditure cost, but it is not sufficient enough to invest in some area and to sustain even the existing service and discharging its obligations or mandates.

Similar studies have been carried out in both Asosa and Ambo towns. For instance Asefa Delesho(2006) has identified institutional, financial, human and mater resources constraints as the main challenges of water supply in Asosa town. Chala (2008) identified limited community participation; poor water distribution design; absence proper problem solving project in the sector, limited soil and water conservation works, limited capacity and unwillingness to understand and serve the will of the community as the main factors that affect water service delivery in Ambo town.

\section{Conclusion and Recommendations:- \\ 5.1 Conclusion}

The water supply of adequate quantity and accessible quality is one of the basic needs of human being. But the provision of potable water was ineffective and inefficient in Wolaita Sodo town. Thus the problem of drinking water become common and remains problematic in the town due to tremendous population growth at the rate of $2.5 \%$ and the spatial expansion of the town which outstripped its ability to supply sufficient water to its inhabitants.

The majority of people who reside in the town have no access to safe and adequate water service delivery. Because of this, most of them are forced to fetch unprotected and unsafe water by traveling along distances. They are also enforced to purchase water from water vendors found in the town at unaffordable price which cost them from 1.50 to 3.0 Ethiopian Birr per a container.

The status of water supply is very low in the town during the dry season because of lack of soil and natural resource conservation practices, climatic condition, and laziness of Wolaita Sodo Water Supply department. Most of the employees of the sector are not well experienced and have no appropriate educational background and training in water service delivery. The existing sources of potable water are both surface and ground water which reaches the users through private and public connection. The water service interrupts for more than two days per week. This leads the residents to travel long distance to fetch unsafe water with low price. As a result of this they are easily vulnerable to water related diseases. The major constraints of distribution system identified are management problem, mismatch of population number and service provision, limited number of public tap and reservoirs, and it's unfair distribution throughout town, problems of pump machine and pipeline out data, financial problems, working under capacity, absence of well- prepared pipe line design and lack of proper projects and program in the sector. 
The water tariff set in the town is not properly formulated and does not enable the office to cover all cost including the investment cost recovery. The majority of the victims of the problem are poor as they cannot afford the service charge. Thus is observed that the water supply approach in the town concentric at as on traditional system of service coverage, service priced and mandated in situational arrangement for the service delivery.

Moreover, due to inadequate water supply, large number of people waiting for private meter connections in the suburban part of the town; traveling long distances every day to fetch water at the tariff that could not afford the poor and riches fairly; there are no environmental protection and conservation works to provide water for the society at the required amount constantly. Therefore, water supply in Wolaita Sodo town in general is unsustainable; it is socially inequitable, economically inefficient and environmentally unsound.

\subsection{Recommendations}

Improving the existing water supply service in the town in terms of quantity, reliability and sustainability plays a crucial role in upgrading the socio- economic welfare of the people who reside in Wolaita sodo town. Thus, the following measures need to be taken to reverse the existing challenges of water service delivery:

1. Conduct detail study; the Wolaita Sodo Water Supply Organization and other concerning bodies like NGOs conduct a study on both underground and surface water to create a potential source of water supply if financial and environmental conditions allow. The organization should design appropriate policy and planning on the development of adequate, reliable, fair, sustainable and effective water supply should be established based on better understanding of what impediments are there in water supply management and what improvement in water supply service people need and willing to pay;

2. Demand Management; manage the demand by controlling water or loss from pipe leakage and consumption through the use of meters and tariff that are set in accordance with the volume of water consumption;

3. Community participation in decision making; involving the community and CBOs at all levels of water supply program and allow private sector involvement in different components of water supply service such as provision of pipe lines, meters, equipment, machines etc. In addition to this NGOs should take part in rehabilitation of already constructed projects to minimize financial burden of the mandated agency; Wolaita Sodo Water Supply Organization (WSWSO).

4. Resource mobilization; mobilizes resources required to bridge the financial gap. This may include organizing donor's conference, meetings with supply development program at meetings of the general public;

5. Short term credit; since the poor segments of the urban community cannot afford the cost of meter connection charges, pipes, meters and other necessary inputs should be provided on the basis of shorter credit in the form of either individual or group lending to enable the poor people to afford the services;

6. Equitable distribution; water points and pipes ought to be evenly distributed in order to address the problem of the low income group. Installing additional public water points would narrow the gap between demand and supply taking in to consideration the number of people, density and distance between water points ; strengthening the institutional capacity; the institutional structure should be staffed with qualified personal and equipped with the needed facilities;

7. Flexibility of rules and regulations; rules and regulations regarding staff payment and benefits should be flexible realizing that required staff otherwise may not be available; using water reservoirs; containers are the quadrant for frequent interruption of water supply. It solves the problem of complete absence of water supply by storing water. Therefore, it is important to agitate the absence of water supply especially during maintenance and peak dry season.

8. Employing appropriate technology; the technology that can meet appropriate standards and can have adequate spare part and fittings should be applied, even in the long term the use of solar energy rather than electricity would be appreciated.

9. Controlling squatter settlements; illegal spatial expansion of the town across the municipal boundary of the town makes the extension of pipe lines and the distribution of the water point's difficulty and leave out the peripheral areas out of the reaches of potable water. Therefore, rules and regulation ought to set to control such illegal settlements around the town.

\section{Bibliographies:-}


1. Armstrong and kilter (2008): International benchmarking network for utilities of water source, USA, Oxford University press.

2. Asnake Zemenay (2012); Assessing the challenges of sustainable water supply in Harare region. The case of Harare town, Addis Ababa, Ethiopia

3. Asefa Delesho (2006): urban water supply, the case of Assosa town. Addis Ababa, Ethiopia. Berkete Belay (2006): Assessing of water supply system in selected urban poor area of Addis Ababa, Ethiopia.

4. Chala Deyessa (2011): An assessment of urban water supply and sanitation, the case of ambo town, Addis Ababa, Ethiopia.

5. Donald and Kay (2008): Issue of water resource and strategies, USA, New York City press

6. The FDRE government. (2005/06). The Plan for Accelerated and Sustainable Development to End Poverty (PADSEP). Addis Ababa, Ethiopia.

7. The FDRE Central Statistical Agency. (2006). Welfare monitoring survey analytical reports. A Statistical Bulletin. Source of drinking water. Addis Ababa, Ethiopia.

8. The FDRE Central Statistical Agency. (2007). Welfare Monitoring Survey Analytical Report 339-A Statistical Bulletin. Toilet facilities. Addis Ababa, Ethiopia.

9. The FDRE Central Statistical Agency. (2004). Welfare Monitoring Survey Analytical Report Welfare Monitoring Survey Report. Ethiopia

10. FDRE. (2008). The Ministry of Water Resource Development: Water Supply and Sanitation Access Planning Implemntation Enhancement Guideline. ADDis Ababa: FDRE July 2008.

11. Gebre Amanuel (2004): Water supply in Ethiopia, an introduction to environmental Practice

12. IRC (2010): International reference center for community water supply and sanitation publisher, Netherland

13. MOFCD, (2006). Ministry of Finance and Economic Development: Plan FOR accelerated and sustained Development to end poverty(PASDEP). Addis Ababa.

14. WSWSS (2009). Wolaita Sodo Water Supply and Sanitation Sector Document . Wolaita Sodo, Etjiopia.

15. UN Development Group. (2010). Task Force on Water and Sanitation. Millennium Project. Pathak B, Rajola V. and Rajnish, K. (2002). Water supply \& Sanitation status in five African nations; Sulabh International Academy of Environmental Sanitation In collaboration with UnitedNations Human Settlements Program (UN-Habitat).

16. UN-Habitat-Sodo profile. (2006). Retrieved from: www.un-habitat.org. UN MGD database. (2006). Retrieved from: www.unmgd.org

17. UNDP. (2006). Human Development Report beyond Scarcity : Power, Poverty and the Global water Crisis. Paris: United Nation Research Center Institute.

18. UNESCO. (2005). United Nations Economic and Social Council : Public - Private Partnerships (PPPS) For Public Service Delivery : Water Supply and Sanitation. Addis Ababa, Ethiopia.

19. UNICEF. (2006). Meeting Development in Small Urban centers ; water and sanitation Rural Challenge Of the Decade. Geneva: Geneva Research Development Institute. 